\title{
Fatores determinantes do comportamento do consumidor em relação aos restaurantes vegetarianos e perspectiva de um restaurante indiano em Cascavel/PR
}

\author{
Thiago Pereira de Souza Paetzhold \\ Bárbara Françoise Cardoso** \\ Pery Francisco Assis Shikida****
}

\begin{abstract}
Resumo
Este trabalho tem como objetivos verificar a satisfação do consumidor em relação aos restaurantes vegetarianos existentes na cidade de Cascavel e o comportamento desse perante a inserção de um restaurante indiano na cidade. Nesse sentido, analisam-se os pontos fortes e os fracos, as oportunidades e ameaças existentes no contexto dos restaurantes vegetarianos em Cascavel. Para tanto, foi formulado um questionário cuja aplicação realizou-se por meio de intervenção aleatória com entrevistados nos restaurantes vegetarianos e nas ruas. Os resultados mostraram que o consumidor de Cascavel está satisfeito com o atendimento dos restaurantes vegetarianos da cidade, havendo aprovação de $90 \%$ dos entrevistados. Quanto ao comportamento em relação à inserção de um restaurante indiano na cidade, $66 \%$ dos entrevistados demonstraram vontade de conhecer a alimentação indiana; e $44 \%$ estariam dispostos a pagar entre $R \$ 10,00$ e $R \$ 15,00$ para almoçar e $47 \%$ estariam dispostos a pagar entre $R \$$ 25,00 e $\mathrm{R} \$ 50,00$ para jantar em um restaurante indiano. As oportunidades encontradas podem suprir os pontos fracos dos restaurantes, caso haja investimentos maiores para ampliação e diversificação, além de divulgação. As ameaças também podem ser minimizadas com mais investimentos em marketing e propaganda, além de mostrar à população os benefícios de uma alimentação saudável.
\end{abstract}

Palavras-chave: Comportamento do consumidor. Cultura indiana. Vegetarianismo.

* Graduado em Administração de Empresas pela Universidade Bandeirante de São Paulo (UNIBAN - Campus Cascavel). Acadêmico do Curso de Especialização Lato Sensu em Engenharia Econômica e Análise de Projetos da Universidade Estadual do Oeste do Paraná (Unioeste - Campus Toledo). E-mail: tpaetzhold@msn.com

** Doutora em Desenvolvimento Regional e Agronegócio pela Universidade Estadual do Oeste do Paraná (UnioestE - Campus Toledo). Mestre em Desenvolvimento Regional pela Universidade Federal do Tocantins (UFT - Campus Palmas). Bacharel em Gestão do Agronegócio pela Universidade Federal de Viçosa (UFV - Campus Viçosa). Pesquisadora RHAE na Fiasul Indústria de Fios. E-mail: barbarafcardoso@gmail.com

**** Doutor em Economia Aplicada pela ESALq/USP, com pós-doutoramento em Economia pela Fundação Getúlio Vargas - São Paulo. Mestre em Economia Agrária pela ESALQ/USP. Bacharel em Ciências Econômicas pela Universidade Federal de Minas Gerais (UFMG - Campus Belo Horizonte). Professor associado da Universidade Estadual do Oeste do Paraná (Unioeste - Campus Toledo), no curso de Ciências Econômicas, no Programa de Mestrado em Economia e no Programa de Mestrado e Doutorado em Desenvolvimento Regional e Agronegócio. E-mail: peryshikida@hotmail.com

http://dx.doi.org/10.5335/rtee.v23i49.8259

Submissão: 14/10/2016. Aceite: 23/08/2017. 


\section{Introdução}

O comportamento do consumidor é um ato mutável que apresenta mudanças constantes, conforme as condições de consumo, modificadas para satisfazer as necessidades básicas do ser humano. Dentre as mutações de consumo dos indivíduos merecem destaque os hábitos alimentares que acompanham as mudanças de estilo de vida. A busca por uma vida mais saudável leva os indivíduos a incorporarem, em sua dieta, alimentos mais saudáveis.

A mudança nos hábitos alimentares pode ocorrer devido às alterações naturais do sistema econômico, como a falta de algum alimento, ou por opção do próprio indivíduo. Diversas pessoas optam por uma alteração nos hábitos alimentares, na qual deixam de consumir carne e até outros produtos de origem animal, trata-se da forma de alimentação vegetariana.

São vários os motivos que contribuem para que uma pessoa adote o vegetarianismo, como fatores éticos, ambientais, econômicos e de saúde (SPENCER, 2002). Além desses aspectos, Melina (1998) aponta outros motivos pelos quais os indivíduos se tornam vegetarianos, sendo que os principais estão relacionados aos direitos dos animais e à religião.

Os hábitos alimentares também estão ligados à cultura de um país. Na Índia, por exemplo, onde grande parte da população é budista e hindu (religiões que priorizam o respeito pelos seres vivos) os cereais e os frutos são tidos como a mais equilibrada forma de alimentar a população. Os brâmanes, membros mais altos do sistema de castas indiano são, desde há muitos séculos, vegetarianos, pois a carne era tida como o alimento mais poluente, por envolver o contato com animais mortos. Concomitante com essas práticas religiosas, certos exercícios, como o Yoga, associaram-se ao não consumo de carne para alcançar a harmonia e ascender a patamares espirituais superiores (SPENCER, 2002).

$\mathrm{Na}$ China, o ato de não comer carne está relacionado, principalmente, à religião budista, a qual condena o excesso de carne e valoriza os vegetais na busca do bem-estar do ser humano (SPENCER, 2002). Contudo, Beig (2009) afirma que o budismo não impõe o vegetarianismo, mas o considera uma forma de alcançar um dos seus fundamentais princípios, que é a rejeição à violência e o respeito absoluto por qualquer forma de vida.

No Brasil, o ato de não comer carne não está ligado à religião. Existem hábitos alimentares diferentes que variam conforme a região do País. Nas regiões Norte e Centro-Oeste, o consumo de peixe e frutas é maior do que nas demais regiões; na região Sul, a carne bovina é muito consumida devido à tradição do "churrasco 
gaúcho"; no Nordeste e Sudeste, predomina o consumo de cereais vis-à-vis às demais regiões do País. A cultura vegetariana e/ou vegana não é característica do Brasil, tendo sido inserida com a migração de outras culturas, como a chinesa e indiana, por exemplo (RECINE; RADAELLI, 2008).

Nesse contexto, o Paraná - estado localizado na região Sul do Brasil - possui influência alimentar, principalmente, dos italianos e alemães. Cascavel encontra-se na região Oeste do estado que, conforme Priori et al. (2012), foi colonizado por europeus, sobretudo eslavos, poloneses, ucranianos, alemães e italianos.

Todavia, em Cascavel, os quatro restaurantes vegetarianos existentes no município são de propriedade de estrangeiros, sendo dois imigrantes da China e dois de Taiwan. Assim sendo, cabe um estudo sobre o comportamento do consumidor de Cascavel perante a inserção de um restaurante vegetariano de outra cultura, visto que as culturas chinesa e taiwanesa são praticamente as mesmas. Destarte, este trabalho busca verificar a satisfação do consumidor de Cascavel em relação aos restaurantes vegetarianos existentes, além de verificar qual seria o comportamento do consumidor perante a inserção de um restaurante indiano. Ademais, análises dos pontos fortes e fracos e das oportunidades e ameaças disponíveis no contexto dos restaurantes vegetarianos de Cascavel fazem-se necessárias para fornecer aos restaurantes uma solução em face de uma possível mudança de comportamento do consumidor.

A escolha por um restaurante indiano está baseada na alimentação saudável e predominantemente vegetariana, como a Samosa, que é um pastel indiano recheado principalmente com feijão e/ou outros grãos ou com a proteína de soja; e outros alimentos como o arroz com curry e vegetais; feijão branco com diversas especiarias e vegetais; grão-de-bico cozido; estrogonofe de proteína de soja; dentre outras diversas alternativas de combinações. Além de dispor de um tempero diverso do que os brasileiros são habituados, a alimentação supracitada é nutritiva, saudável e sustentável (SINGER, 2010). Dessa forma, um restaurante indiano seria uma opção para o público vegetariano.

Isso posto, este trabalho encontra-se estruturado em cinco seções, sendo a primeira esta breve introdução. Na segunda seção, está o approach teórico, ressaltando o comportamento do consumidor, com ênfase na alimentação saudável vegetariana. Na terceira seção, encontram-se os procedimentos metodológicos desta pesquisa, a qual explana sobre o método utilizado para o desenvolvimento dessa, isto é, formulação e aplicação de questionário. Os resultados estão expostos na quarta seção. E, por fim, a quinta seção apresenta as conclusões. 


\section{Breve approach sobre o comportamento do consumidor}

O consumidor faz parte de um sistema produtivo dentro do qual seu comportamento determina, de certa forma, o que será produzido. É o consumidor que envia o feedback às empresas confirmando a aceitação ou não dos produtos comercializados. Tal aceitação é demonstrada por meio do aumento ou da redução do consumo, o que caracteriza o comportamento do consumidor (ENGEL; BLACKWELL; MINARD, 1995).

Para Johns e Pine (2002), o consumidor deve ser tratado como um grupo ou segmento de mercado que apresenta coletivamente as mesmas atitudes e comportamentos relacionados ao que consumir. Contudo, quando separados individualmente conforme suas atitudes, pode-se restringir o tipo de comportamento, facilitando o estudo sobre o que os levam a consumir ou não determinado produto, ou seja, o comportamento do consumidor.

O estudo do comportamento do consumidor envolve a análise das ações e atitudes dos indivíduos em relação à aquisição e ao uso de bens e serviços. A teoria do comportamento do consumidor considera alguns aspectos que restringem e/ou limitam a escolha do consumidor por determinado produto. Tais aspectos são, mormente, a restrição orçamentária e as preferências e gostos. A restrição orçamentária diz respeito à restrição de consumo que os indivíduos têm devido à renda limitada. Dessa forma, o indivíduo está constrito a consumir, no máximo, o valor de sua renda. No caso das preferências e gostos, esses aspectos são subjetivos, sendo diferentes para cada indivíduo. $\mathrm{O}$ indivíduo terá preferência por consumir um produto que ele julga "melhor" do que outros, considerando sua restrição orçamentária (ENGEL; BLACKWELL; MINARD, 1995; MANKIW, 2013).

Além desses fatores que restringem o que os indivíduos consumirão, deve-se considerar que o comportamento do consumidor é influenciado por fatores culturais, sociais, pessoais, psicológicos, biológicos, históricos e de mercado, além da grande influência da mídia, que determina o que é tendência de consumo (ENGEL; BLACKWELL; MINARD, 1995; NEVES; CASTRO, 2003; ROZIN, 2006; TEIXEIRA, 2010; ASSIS, 2011).

Para Teixeira (2010) e Assis (2011), os fatores culturais estão relacionados à cultura da sociedade na qual o consumidor faz parte, isto é, às tradições e costumes ligados à alimentação, vestuário, modo de agir e falar, etc. Esses fatores são incorporados ao consumidor desde seu nascimento, quando lhe é ensinado o que é certo 
e o que é errado. Os fatores culturais são reforçados não somente pela família, mas também pelas escolas, igrejas e grupos sociais dos quais o indivíduo participa. Esses grupos são caracterizados como parte dos fatores sociais, que também influenciam o comportamento do consumidor. A esses grupos acrescentam-se os amigos, colegas de trabalho e outros grupos sociais.

Karsaklian (2008) afirma que os mesmo hábitos alimentares fazem parte da cultura de uma sociedade. Diversas nações possuem hábitos distintos, sendo que o que é permitido em uma cultura pode não o ser em outra. Por exemplo, a cultura norte-americana inclui em sua alimentação ostras, mas não escargots, que é um prato apreciado na França; os judeus comem peixe e não comem carne suína; essa é apreciada pelos indianos que não comem carne de gado, devido ao fato de a vaca ser um animal sagrado; e na cultura chinesa estão incluídos cobras e gafanhotos, que não são bem aceitos pelas demais culturas.

Os fatores pessoais são aqueles relacionados ao ciclo de vida do indivíduo, ou seja, idade, gênero, ocupação, personalidade, etc. Tais fatores determinarão as preferências e os gostos do consumidor, que moldarão o padrão de consumo dos indivíduos. À medida em que o indivíduo muda de fase na vida, seus gostos e preferências também mudam, moldando novamente seu padrão de consumo (ENGEL; BLACKWELL; MINARD, 1995; NEVES; CASTRO, 2003; TEIXEIRA, 2010; ASSIS, 2011).

Giampietri Finco e Del Giudice (2016) argumentam que os fatores psicológicos podem ser explicados pela teoria de Ajzen, a Teoria do Comportamento Planeado. ${ }^{1}$ De acordo com essa teoria, o comportamento do consumidor é determinado pela intenção de comportamento que, por sua vez, é influenciado pelas atitudes, normas subjetivas e controle percebido de cada um dos indivíduos. Ou seja, os fatores psicológicos estão ligados aos fatores culturais e pessoais dos indivíduos. Rozin (2006) acrescenta argumentando que os fatores psicológicos são preeminentes, sendo predominantes as expectativas sobre sabor, conveniência e saúde.

Para Rozin (2006), os fatores biológicos podem ser tanto conscientes quanto inconscientes. Os indivíduos escolhem determinados alimentos buscando suprir suas necessidades nutricionais (carboidratos, proteínas, vitaminas, etc.), muitas vezes, de forma inconsciente. Os fatores históricos, por sua vez, estão ligados ao processo histórico pelo qual o indivíduo passou, isso é, a forma como sua região foi colonizada, a religião que lhe foi imposta pelos pais no dia do seu nascimento, as tradições familiares, entre outros aspectos. Tudo o que aconteceu com suas gerações passadas influenciam na sua escolha de consumo, ou seja, esse fator está relacionado aos fatores culturais. 
Os fatores mercadológicos, para Teixeira (2010) e Assis (2011), dizem respeito às condições da economia, como nível de inflação, disponibilidade de crédito, oferta de produtos, taxa de juros, etc. Esses fatores determinam a capacidade de compra e a disposição do indivíduo em pagar por determinado produto e estão diretamente ligados à restrição orçamentária do indivíduo.

Paixão (2011, p. 35), corrobora com o exposto, afirmando que "estudar o comportamento do consumidor é entender seus pensamentos e suas ações, bem como as influências que ele sofre na hora da decisão de compra”. Tal decisão pode ser de três tipos, a saber:

Decisão rotineira ou habitual - o consumidor está disposto a gastar o menor tempo possível na compra de produtos simples, baratos e conhecidos.

Decisão limitada - o consumidor quer investir pouco tempo na compra de produtos em que se envolve um pouco mais.

Decisão extensiva ou complexa - existe uma demanda maior de investimento de tempo e envolvimento do consumidor (PAIXÃO, 2011, p. 36).

Além disso, a resistência do consumidor também é um aspecto que não pode ser ignorado. De acordo com Eckhardt e Mahi (2012), tal resistência é mutável e depende do contexto; ela está relacionada com a habilidade do consumidor em

No que se refere ao comportamento do consumidor de alimentos, Pollonio (2005) argumenta que tal comportamento é influenciado por tendências mundiais, tais como o envelhecimento da população, o tamanho reduzido das famílias, a inserção das mulheres no mercado de trabalho, etc. Essas tendências moldaram um padrão de consumo caracterizado pela busca de uma alimentação e de um estilo de vida mais saudáveis.

Rozin (2006) explicita que a escolha pela mudança alimentar é uma característica da evolução humana, em que, primeiramente, a sociedade era vegetariana e passou a ser carnívora com a evolução, mudando-se da floresta para a savana na busca de nutrientes. Atualmente, a sociedade construiu sua moradia fixa e voltou a ser vegetariana, mas, dessa vez, pela busca de uma vida mais saudável.

O consumidor moderno, em relação àquele destacado por Rozin (2006), possui novos hábitos alimentares e atitudes relacionadas ao consumo, dentre os quais se destacam a maior preocupação com a saúde, com o meio ambiente, a segurança alimentar e a segurança do alimento. Para esse consumidor, o aumento do consumo de frutas, vegetais e verduras está relacionado a um estilo de vida saudável, o qual busca o consumo de produtos frescos. Nesse contexto, alguns indivíduos procuram esse estilo de vida saudável no vegetarianismo e/ou veganismo (POLLONIO, 2005). 
De acordo com Johns e Pine (2002), o consumidor moderno possui exigências que antes não eram evidenciadas, tais como a busca por produtos orgânicos, rastreabilidade dos alimentos, valores nutricionais, mudança nos hábitos alimentares (produtos sem carne, sem glúten, sem lactose, por exemplo), entre outros. Tais aspectos permitem às indústrias de serviços alimentícios se especializar e oferecer ao consumidor alimentos personalizados, visto que ele faz parte de um nicho de mercado que as indústrias que produzem em grande escala ainda não conseguem atender adequadamente. A indústria de serviços alimentícios, que engloba hotéis, restaurantes, lanchonetes, entre outros, se diferencia das demais indústrias pelo fato de esta se preocupar com a qualidade do produto mais do que com a quantidade produzida. Além de visar sempre à qualidade, essa indústria tem de se preocupar com a riqueza de nutrientes em cada alimento oferecido, proporcionando ao consumidor um alimento nutricionalmente balanceado.

Buscando entender como esse consumidor moderno se comporta e quais as características relacionadas às suas atitudes, vários estudos foram desenvolvidos no mundo todo, em várias áreas (economia, administração, marketing, psicologia, sociologia, etc.). Naya e Capps (1994), por exemplo, estudaram o comportamento do consumidor quanto à escolha do restaurante de acordo com os extratos sociais. Binkley (1998) mostrou que nas áreas metropolitanas, as diferenças demográficas e de renda são mais importantes na decisão do consumidor sobre o tipo de comida a consumir do que a densidade populacional. Wilcock et al. (2004) ressaltam as diversas atitudes dos consumidores em relação à segurança dos alimentos, destacando que tal diversidade se baseia em vários fatores, principalmente, nos aspectos demográficos e socioeconômicos. Trew et al. (2006) relacionaram as escolhas alimentícias dos adolescentes com o vegetarianismo, afirmando que as escolhas pelo consumo de determinados alimentos provém da fase da vida de cada indivíduo. Giampietri et al. (2016) investigaram a diferença nas atitudes dos consumidores italianos e brasileiros no que se refere ao consumo de alimentos produzidos pelos agricultores locais.

Johns e Pine (2002) acrescentam que o consumidor, no que se refere à alimentação em restaurantes, observa alguns atributos relacionados ao serviço antes de decidir por frequentar ou não o local, tais como características que fazem com que o local seja desejável de frequentar, considerando-os em diferentes níveis de importância. Tais atributos estão relacionados ao preço, qualidade do alimento, conveniência da localização, satisfação das expectativas, entre outros fatores. Em um estudo do comportamento do consumidor em que são considerados tais atributos, 
a análise pode ser feita antes (expectativa) e depois (evolução do desempenho) da experiência.

Pelo lado da firma, o comportamento do consumidor pode ser observado pelo marketing. Perner (2017) expõe que o estudo do comportamento do consumidor ajuda as firmas a elaborarem melhor suas estratégias de marketing, e envolve $o$ estudo de indivíduos, grupos ou organizações e processos usados para selecionar, proteger, usar e dispor de produtos, serviços, experiências ou ideias que satisfazem as necessidades e os impactos que estes processos têm sobre os consumidores e a sociedade.

\section{Principais aspectos sobre o vegetarianismo}

Os alimentos vegetais possuem todos os nutrientes necessários para a manutenção de uma vida saudável. Os indivíduos que decidem manter uma dieta alimentar à base desses alimentos são considerados vegetarianos, isto é, são pessoas com escolhas alimentares que excluem carne de todos os tipos (gado, frango, peixe e outros animais) e produtos que os contenham (como os industrializados). Esses indivíduos consomem grãos, hortaliças, frutas, legumes, oleaginosas e seus produtos, entre outros (WINKLER, 2004; NUNES, 2010).

Hoek et al. (2004) afirmam que o conceito de vegetarianismo não é muito direto e diverge entre os estudiosos, sendo de senso comum o fato de que as pessoas deixam de comer carne de qualquer animal. American Dietetic Association (ADA, 2003) e Vegetarian Society (2016) expõem que a dieta vegetariana pode ser classificada em basicamente sete tipos, a saber: (1) lacto-vegetarianismo - caracteriza-se pelo consumo de vegetais, leite e seus derivados; (2) ovo-lacto-vegetarianismo - além da dieta do lacto-vegetarianismo, acrescenta-se o ovo no consumo; (3) ovo-vegetarianismo - a dieta inclui ovos, mas não produtos lácteos; (4) vegetarianismo estrito ou veganismo - exclui-se todos os alimentos de origem animal; (5) frutarianismo - consiste em uma dieta que envolve alimentos pouco cozidos ou processados, incluindo frutas cruas, grãos e frutos oleaginosos na dieta; (6) semi-vegetarianismo - dieta que restringe apenas carne vermelha, podendo ser ingeridas carnes brancas; e (7) macrobiótica - é a mais radical das dietas vegetarianas, pois consiste na eliminação gradual não somente da carne, mas também da água, frutas e hortaliças.

Independentemente da dieta adotada, Meirelles, Veiga e Soares (2001) argumentam que existem muitos benefícios para os adeptos do vegetarianismo, embora não haja consenso na literatura quanto aos benefícios à saúde. Contudo, os autores

Teoria e Evidência Econômica - Ano 23, n. 49, p. 436-461, jul./dez. 2017 
expõem que a dieta vegetariana pode estar associada à redução dos riscos de algumas doenças, tais como obesidade, diabetes mellitus, doença cardiovascular, câncer e osteoporose. Por outro lado, aspectos negativos desta dieta também devem ser destacados, tais como implicações negativas durante a fase de crescimento do indivíduo quando a mãe é lactante e, posteriormente, no período escolar e na adolescência, devido à falta de alguns nutrientes que são essenciais ao desenvolvimento do ser humano nas fases iniciais da vida.

Além da questão alimentar, o vegetarianismo também envolve uma cultura de relação harmoniosa entre os seres humanos e a natureza; é considerado um estilo de vida, em que o indivíduo preza pelo bem-estar animal (HOEK et al., 2004). Twigg (1979) argumenta que o vegetarianismo contém uma longa dimensão experimental, é pensado por ações e objetivos bem como teorias e conceitos. Alguns dos conceitos envolvem uma forte relação emocional do consumidor com a natureza, de tal forma que essa dieta era usada na medicina holística com o objetivo de tratar doenças do corpo ao invés de se proceder com intervenções cirúrgicas ou uso de medicamentos. Além dessa relação física, existe também a relação espiritual, a qual está relacionada ao fato de que a alimentação sem a digestão de carnes purifica a alma e o espírito. Existe ainda a relação ecológica, que contempla o equilíbrio da natureza. Por último, tem-se a relação religiosa ou psicológica, na qual o indivíduo, por motivos religiosos ou por comoção, deia de consumir a carne de animais.

Singer (2010, p. 221) complementa afirmando que, "o vegetarianismo implica uma nova relação com os alimentos, as plantas e a natureza”. Tal relação vai além da busca por uma alimentação saudável; inclui também o respeito pela vida animal. É essa filosofia de vida que determinará o comportamento do consumidor em relação à escolha pelo tipo de vegetarianismo que ele seguirá, pois alguns tipos, como o veganismo, por exemplo, além de adotar uma dieta sem alimentos de origem animal, também prega a rejeição ao uso de roupas, sapatos e acessórios que utilizem algum material de origem animal.

Entretanto, a disponibilidade de alimentos para as pessoas adeptas do vegetarianismo é limitada, principalmente se o indivíduo for vegano. Ressalta-se que a disponibilidade de alimentos para quem faz dieta vegetariana vai além dos restaurantes, existindo, atualmente, diversas opções de compra de itens vegetarianos em supermercados, praças de alimentação dos grandes estabelecimentos comerciais e até mesmo pela internet. Alguns consumidores optam por diversidades vegetarianas, incluindo bebidas vegetais e análogos de carne, como a carne de soja que é feita com proteína de soja. 
Outrossim, deve-se considerar o fato de que a consciência ambiental e relacionada à saúde está cada vez mais presente na vida do ser humano. Paquette (2005) argumenta que em todo o mundo há uma constante evolução da consciência de que o ser humano precisa integrar hábitos saudáveis ao estilo de vida, no qual está incluída a alimentação vegetariana e vegana, dentre outras dietas e restrições alimentares.

Ainda conforme Paquette (2005), as necessidades da alimentação saudável são vistas como um dos diversos indicadores que direcionam os hábitos alimentares de cada indivíduo. Sendo assim, a cada dia aumenta o número de pessoas que estão optando por uma alimentação mais pura e natural por meio do vegetarianismo e veganismo.

\section{Procedimentos metodológicos}

Este trabalho foi desenvolvido por meio de pesquisa de campo, com aplicação de questionário in loco, caracterizando uma pesquisa qualitativa por meio de um estudo de caso múltiplo, uma vez que se consideram diversos consumidores em diferentes situações, conforme Yin (2001). A pesquisa qualitativa pode ser definida como o estudo de um fenômeno analisado no contexto em que ocorre e do qual faz parte. A pesquisa qualitativa por estudo de caso busca entender o fenômeno a partir da perspectiva das pessoas envolvidas em tal fenômeno, considerando o ponto de vista delas (GODOY, 1995).

O questionário foi aplicado em duas etapas: a primeira foi realizada entre os dias 27 de julho de 2016 e 19 de agosto de 2016 em quatro restaurantes vegetarianos em Cascavel, cuja identificação se dará por R1, R2, R3 e R4, e cujos donos serão identificados por P1, P2, P3 e P4, respectivamente; a segunda etapa foi realizada no dia 10 de setembro de 2016, por uma equipe composta por três pesquisadores em quatro pontos da cidade: Calçadão da Avenida Brasil, Rua Padre Champagnat, Rua Paraná e Rua Rio Grande do Sul. Considerando as duas etapas da pesquisa, somou-se um total de 176 entrevistados: 51 pessoas nos restaurantes e 125 nas ruas.

Foram utilizados dois tipos de amostragem. A primeira amostra (pessoas pesquisadas nos restaurantes) é do tipo não probabilística, sendo considerada amostra intencional. Segundo Gil (2008, p. 94), este tipo de amostra "consiste em selecionar um subgrupo da população que, com base nas informações disponíveis, possa ser considerado representativo de toda a população". No caso desta pesquisa, trabalha-se com o subgrupo de pessoas que frequentam restaurantes vegetarianos para

Teoria e Evidência Econômica - Ano 23, n. 49, p. 436-461, jul./dez. 2017 
uma população de pessoas vegetarianas. A segunda amostra (pessoas pesquisadas nas ruas) é do tipo não probabilística, considerada amostra acidental. Barbetta (2002) expõe que esse tipo de amostra normalmente é resultado de pesquisas de opinião, na qual o pesquisador permanece em determinado lugar e entrevista as pessoas que por ali passam. No caso desta pesquisa, a equipe de pesquisadores permaneceu em quatro pontos da cidade de Cascavel para entrevistar as pessoas que passavam.

O questionário foi desenvolvido visando atender ao objetivo desta pesquisa, sendo composto por duas partes. A primeira parte visa entender quais são os consumidores vegetarianos/veganos e qual a percepção deles em relação aos restaurantes vegetarianos. Tal percepção também foi obtida daqueles que não são adeptos a essas dietas. Na segunda parte, insere-se a culinária indiana e questões que visam entender o comportamento do consumidor caso houvesse este tipo de restaurante em Cascavel. Ambas as partes do questionário vão de acordo com o que Johns e Pine (2002) expõem sobre uma das formas de se analisar o comportamento do consumidor: antes da experiência (parte 2) e depois dela (parte 1).

A primeira parte é composta por 10 questões: 8 questões de múltipla escolha e 1 questão de livre resposta e 1 questão de comentários adicionais (não obrigatória). As 8 questões de múltipla escolha foram formuladas de forma a entender se o indivíduo é adepto ao vegetarianismo ou ao veganismo; o tempo que ele é adepto a esta dieta (caso seja); e se está satisfeito com o que é ofertado pelos restaurantes vegetarianos, caso ele os frequente. A questão de livre resposta visa saber quais são os motivos que levam o indivíduo a frequentar os restaurantes vegetarianos.

A segunda parte é composta por 13 questões: 10 questões de múltipla escolha, 2 questões de livre resposta e 1 questão de comentários adicionais (não obrigatória). As 11 questões de múltipla escolha foram formuladas de forma a entender se o indivíduo já consumiu algum tipo de comida indiana; quais os serviços que ele gostaria que um restaurante tivesse; quais as qualidades que mais aprecia em um restaurante; e que tipo de serviço, relacionado ao pedido, ele gostaria que fosse disponibilizado por um restaurante indiano. As duas questões de livre resposta procuram entender quanto o indivíduo gasta para almoçar e jantar em um restaurante qualquer e quanto estaria disposto a pagar para almoçar e jantar em um restaurante indiano.

A análise da questão discursiva foi realizada por meio da análise de conversação que, segundo Gonçalves (2016, p. 289), é composta por análises "eminentemente descritivas da fala dos participantes". Transcreveu-se, nos resultados, ipsis litteris, o que os entrevistados responderam, sendo realizada também análise de discurso para verificar as respostas que se repetiam, com a finalidade de transcrever apenas aquelas que possuíam conteúdo diferente. 
Para a transcrição dos comentários adicionais, os entrevistados foram identificados por números: E1, E2, E3, ..., E176. Tais comentários permitiram a realização da análise da matriz SWOT (Strenghts, Weaknesses, Opportunities, Threats), que é a análise das forças, fraquezas, oportunidades e ameaças identificadas pelos entrevistados. A análise da matriz SWOT permite, por meio da identificação destes aspectos, melhor gerenciamento do negócio. Nesse caso, para melhorar a competitividade dos restaurantes vegetarianos existentes.

Conforme Dantas e Melo (2008), a matriz SWOT é dividida em quatro componentes, os quais possuem interferência do ambiente externo e interno. A Figura 1 mostra essa divisão e a interferência dos ambientes.

Figura 1 - Matriz de análise SWOT

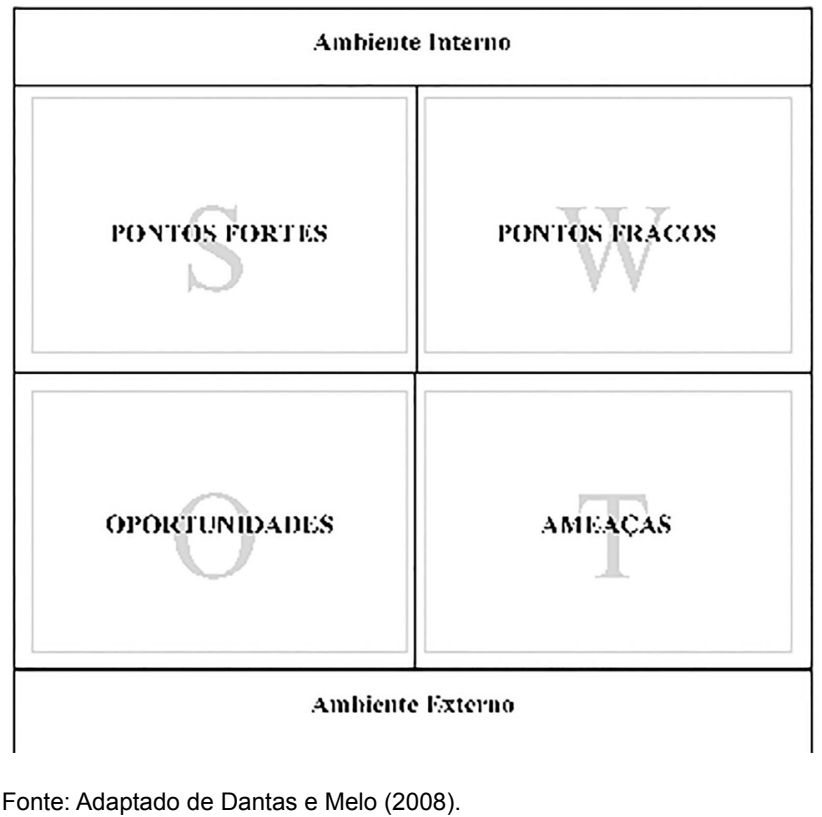

Os pontos fortes e fracos são aspectos que ocorrem dentro da organização. Logo, sua interferência se dá no ambiente interno. A organização é capaz de identificá-los e trabalhar de modo a fortalecer cada vez mais seus pontos fortes e minimizar ao máximo seus pontos fracos. Já as oportunidades e as ameaças são fatores que ocorrem no ambiente externo da empresa, isto é, são aspectos que ela não pode controlar, como a conjuntura econômica, por exemplo, mas pode tentar incorporar (oportunidades) ou amenizar seus impactos (ameaças) (DANTAS; MELO, 2008). 


\section{Análise e discussão dos resultados}

Conforme estimativa publicada em 2016 pelo Instituo Brasileiro de Geografia e Estatística (IBGE), o município de Cascavel possui 316.226 habitantes, sendo que apenas $0,38 \%$ frequentam restaurantes vegetarianos. Esse valor, segundo os proprietários dos quatro restaurantes vegetarianos da cidade, ${ }^{2}$ é uma estimativa que considera apenas os clientes assíduos de segunda a sexta-feira. Contudo, vale ressaltar que não apenas vegetarianos frequentam estes restaurantes, mas também os não vegetarianos, que somam $47,1 \%$ dos entrevistados nesta pesquisa. ${ }^{3}$

Dos que são vegetarianos, a maioria dos entrevistados é adepta desse estilo alimentar há mais de cinco anos (45\%), como mostra o Gráfico 1.

Gráfico 1 - Tempo em que os indivíduos são adeptos da culinária vegetariana

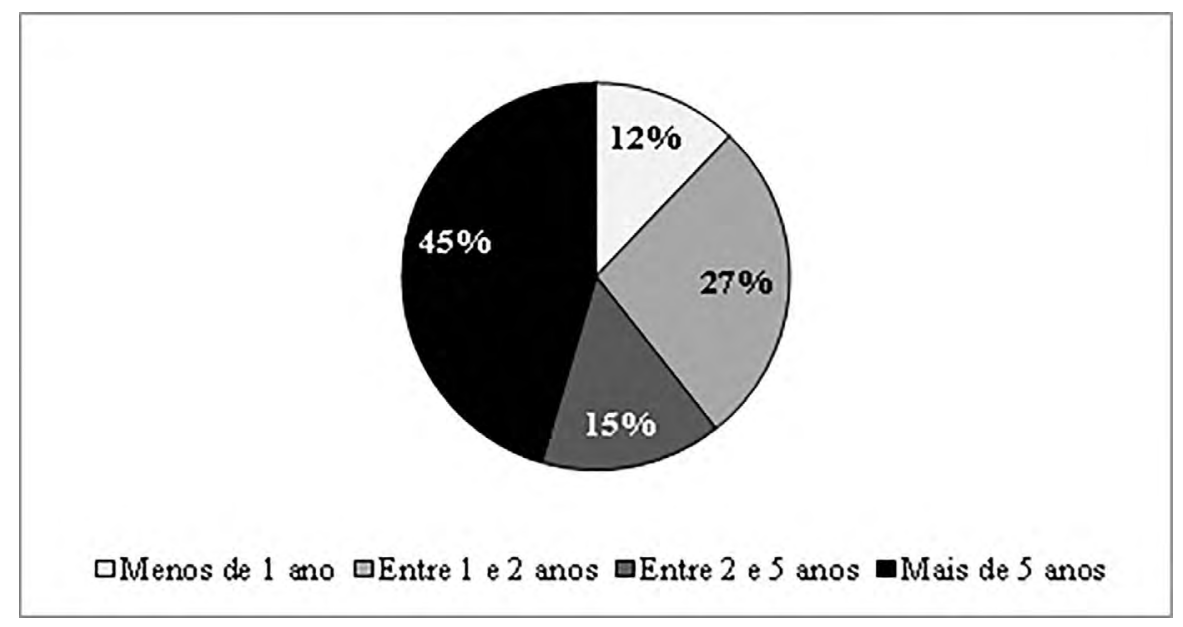

Fonte: Resultado da pesquisa.

Outro fato que merece destaque é que a maior parte das pessoas que frequentam os restaurantes vegetarianos (65\%) é do sexo feminino, o que evidencia que a mulher apresenta maior preocupação com a alimentação. Fica evidente, dessa forma, o fator pessoal (gênero) na escolha pelo consumo de uma alimentação saudável.

De acordo com os proprietários dos restaurantes, quando iniciaram o negócio, a demanda era de aproximadamente 100 indivíduos por semana, alcançando hoje um público de cerca de 1.200 pessoas. Eles ainda acrescentam que, nos últimos dois anos (2014 e 2015), houve um aumento significativo de clientes, porém, não sabem se estes são ou não vegetarianos. 
Conforme os resultados da pesquisa, 25\% dos entrevistados em geral são vegetarianos ou veganos. ${ }^{4}$ Os entrevistados estão, em sua maioria, na faixa etária de 20-25 anos de idade, representando 30\% da amostra, como mostra o Gráfico 2.

Gráfico 2 - Distribuição dos entrevistados por faixa etária

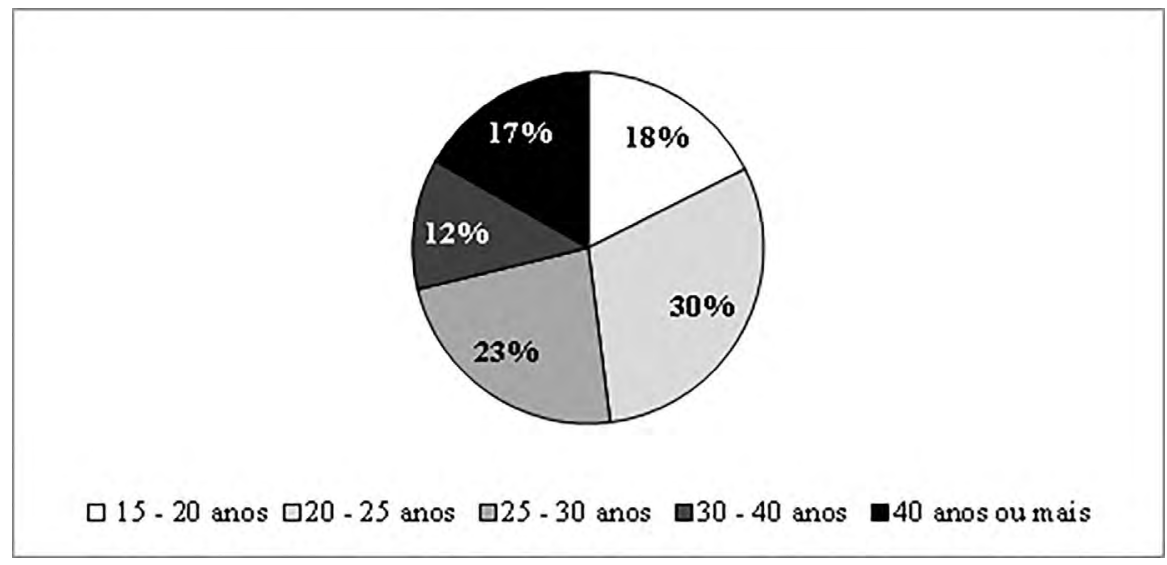

Fonte: Resultado da pesquisa.

Quando questionados sobre a satisfação com o atendimento dos restaurantes vegetarianos, $90 \%$ dos entrevistados afirmaram que estão satisfeitos. Os fatores citados pelos respondentes de sua satisfação e que os levam a frequentar os restaurantes vegetarianos estão dispostos no Gráfico 3.

Observa-se que os motivos da satisfação e que levam o consumidor a ter preferência por frequentar restaurantes vegetarianos podem ser divididos conforme os fatores que influenciam o comportamento do consumidor, expostos por ENGEL; BLACKWELL; MINARD (1995), Neves e Castro (2003); Teixeira (2010) e Assis (2011), a saber:

(a) fatores culturais - sou vegetariano;

(b) fatores sociais - influência de amigos;

(c) fatores pessoais - busca por uma vida saudável/qualidade de vida, qualidade da comida e tempero, e ambiente agradável;

(d) fatores psicológicos - consciência ambiental e dos direitos dos animais; e

(e) fatores mercadológicos - diversidade dos alimentos, comida leve e saudável, falta de diversidade em restaurantes tradicionais e preço acessível. 
Gráfico 3 - Motivos da satisfação e que levam os consumidores a frequentarem os restaurantes vegetarianos

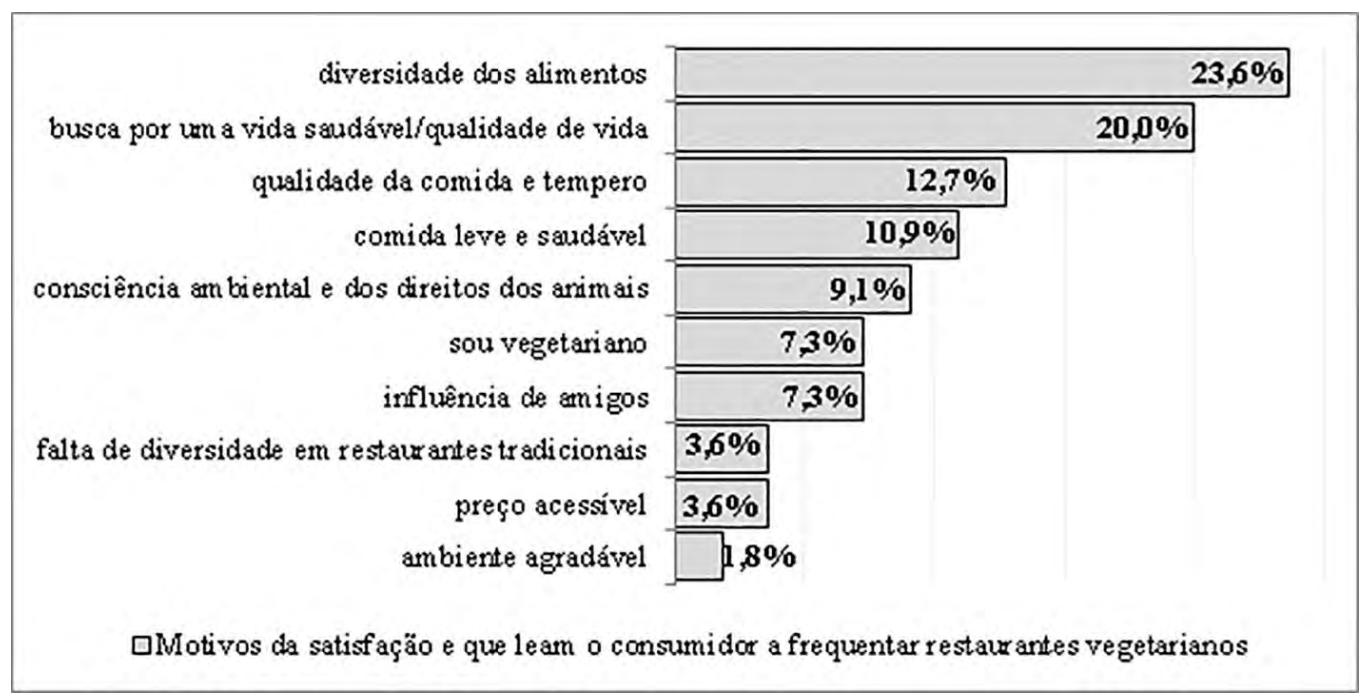

Fonte: resultado da pesquisa.

Considerando que em Cascavel os restaurantes vegetarianos são de propriedade de estrangeiros, a alimentação servida segue, em sua maioria, os costumes da cultura alimentar dos proprietários. Os restaurantes estão localizados no centro da cidade e são de propriedade de chineses e taiwaneses. O restaurante R1, cujo proprietário é taiwanês, foi o primeiro restaurante vegetariano a se instalar em Cascavel. De acordo com P1, o Taiwan se considera um país independente da China, porém, ainda vive alguns conflitos históricos relacionados à colonização japonesa $\mathrm{e}$ à intervenção dos Estados Unidos. Tais conflitos fazem com que os taiwaneses busquem refúgio em outros países, sendo o Brasil um dos países mais procurados por eles. Complementando, P2 afirma que China e Taiwan possuem culturas próximas e, por isso, são muito ligados aqui no Brasil, inclusive em Cascavel, cujo contato é constante.

Dessa forma, e por meio das respostas dos entrevistados, percebe-se que há aceitação de alguns dos consumidores de Cascavel por restaurantes cuja alimentação tem uma proposta saudável e adaptada da culinária de outros países. Nesse contexto, foi inserida a possibilidade de um restaurante de origem indiana, cuja alimentação já é conhecida por $9 \%$ dos entrevistados, e cujo interesse em conhecer tal alimentação foi demonstrado por $66 \%$. 
Daqueles que não conhecem a alimentação indiana, 56\% não tiveram a oportunidade ou o acesso a esse tipo de comida, enquanto $28 \%$ declararam que não têm coragem de experimentá-la. O principal motivo de não vivenciarem essa experiência alimentar é a crença de que a alimentação indiana não agradaria seus paladares. Mais uma vez, percebe-se a influência dos fatores culturais e psicológicos no comportamento do consumidor.

Quanto ao que se espera de um restaurante indiano, foi pedido que fossem enumerados alguns aspectos, de forma a priorizá-los, sendo aqueles com valor 1 os itens de maior importância na visão do consumidor. O Gráfico 4 mostra a relação e o percentual de cada um dos itens.

Gráfico 4 - Qualidades e serviços que se esperam de um restaurante indiano

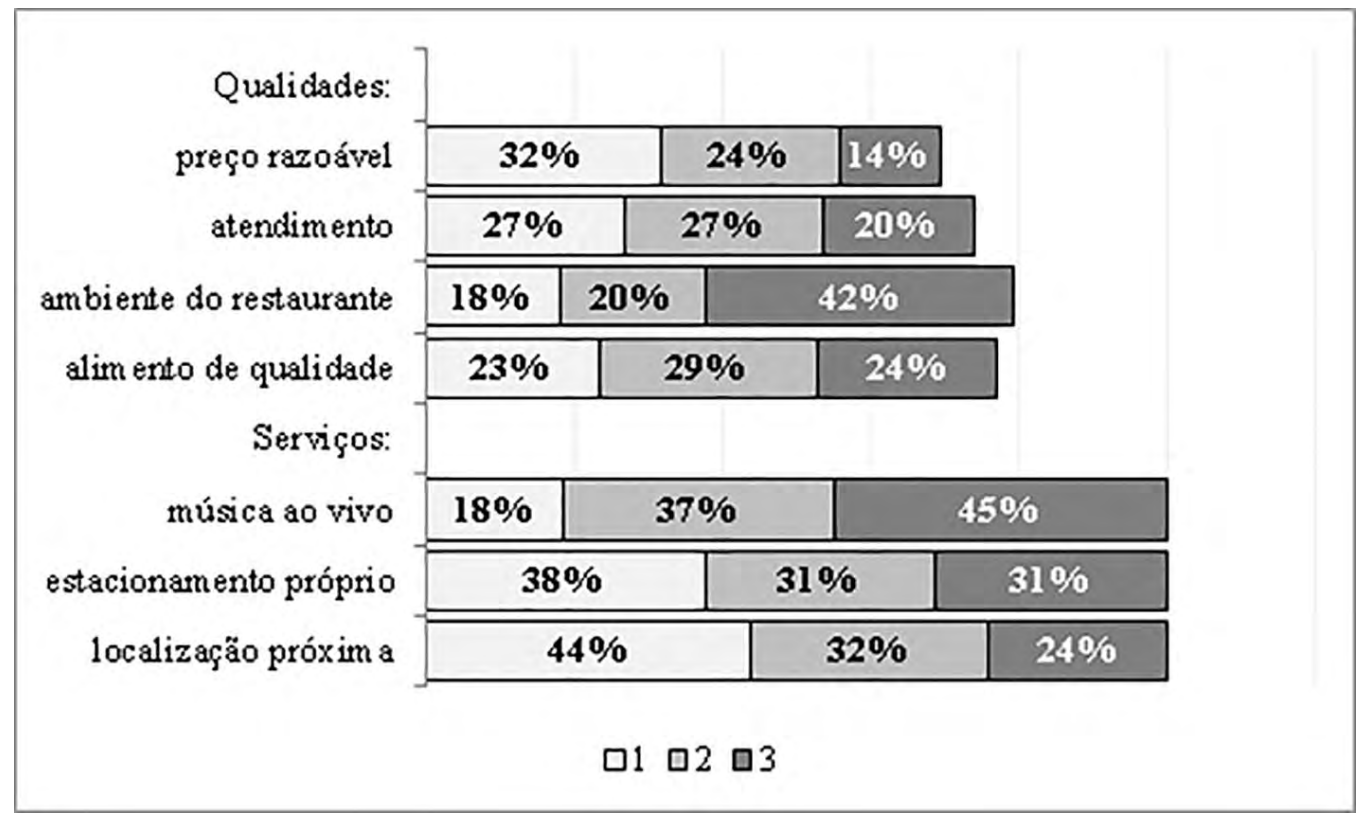

Fonte: resultado da pesquisa.

Percebe-se que, para os entrevistados, o preço e o atendimento são fatores primordiais e, somente depois, a qualidade do alimento. Dessa forma, evidencia-se que os fatores mercadológicos são mais importantes para os consumidores entrevistados. Quanto aos serviços, evidencia-se a preferência por uma localização próxima. 
Considerando que 76\% dos entrevistados frequentam restaurantes pelo menos uma vez por semana, uma comparação sobre o preço pago em restaurantes tradicionais e/ou vegetarianos e o preço que os consumidores estariam dispostos a pagar em um restaurante indiano se mostra interessante. O Gráfico 5 mostra esse cotejo.

Gráfico 5 - Preço pago e disponibilidade a pagar pelos consumidores de Cascavel

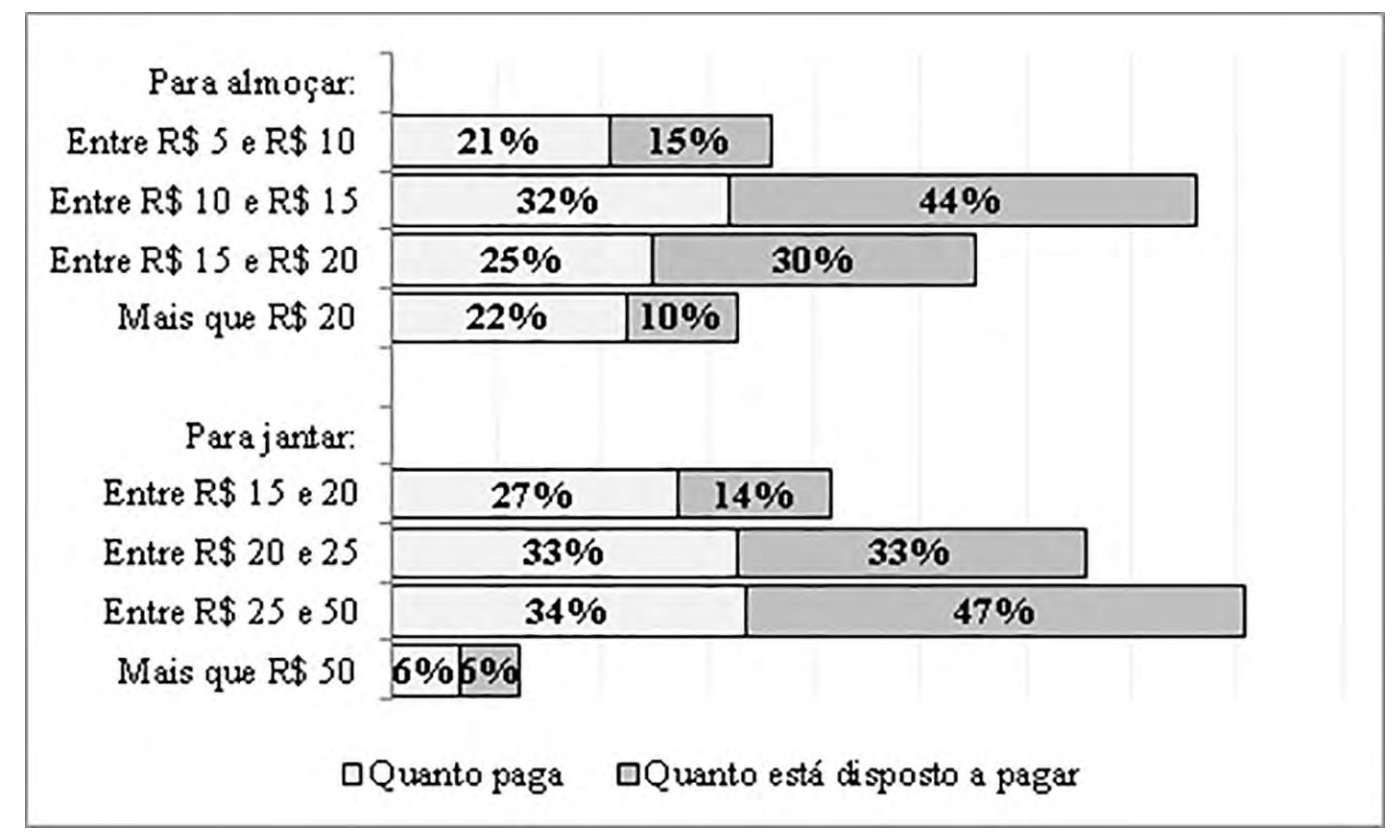

Fonte: resultado da pesquisa.

A maioria dos entrevistados paga entre $R \$ 10,00$ e $R \$ 15,00$ para almoçar em restaurantes tradicionais ou vegetarianos, e entre $R \$ 25,00$ e $R \$ 50,00$ para jantar. A disponibilidade em pagar por um almoço e um jantar em um restaurante indiano também se encontra nestes intervalos de preços.

Essas faixas de preços correspondem à realidade, pois $72,5 \%$ dos entrevistados afirmaram que o custo das refeições em restaurantes vegetarianos é acessível. Em complemento, conforme os proprietários dos restaurantes pesquisados, em R1, $\mathrm{R} 2$ e R3, o preço é de $\mathrm{R} \$ 15,00$ com buffet livre, enquanto no restaurante R4 existe a opção de servir-se somente uma única vez, à vontade, por $R \$ 11,00$ ou a opção de buffet livre por $\mathrm{R} \$ 15,00$. Para comparação, foram consultados quatro restaurantes tradicionais nas proximidades dos restaurantes vegetarianos e nenhum possui 
opção de buffet livre, somente buffet por quilo, com variação de preço entre $\mathrm{R} \$$ 26,99 à $\mathrm{R} \$ 38,99$ por quilo.

Cabe ressaltar que o público dos restaurantes vegetarianos em Cascavel é atingido sobretudo pela divulgação do marketing "boca-a-boca", visto que não são utilizados meios de comunicação para a divulgação dos restaurantes. Os restaurantes tradicionais, por outro lado, incentivam o seu público-alvo por meio de propagandas em rádio, televisão, internet e outros meios. Dessa forma, percebe-se que uma maior divulgação de um novo restaurante vegetariano em Cascavel, proveniente da cultura indiana, abriria perspectiva favorável para fidelizar novos consumidores, além de compartilhar os clientes que já frequentam os demais restaurantes vegetarianos de Cascavel.

A falta de divulgação da existência destes restaurantes ficou evidente nas respostas dos entrevistados quando foi pedido que eles apontassem as carências e falhas dos restaurantes vegetarianos, de modo a aprimorarem os restaurantes, seja por meio de sugestões de cardápio seja para aumentar a fidelização dos clientes. Tais contribuições estão expostas no Quadro 1.

Quadro 1 - Sugestões dos clientes e potenciais clientes para aprimorar os serviços dos restaurantes vegetarianos

\begin{tabular}{|l|l|}
\hline E3 & Criar pratos e saladas que despertem o interesse em consumir ao olhar, fazer formas e cores. \\
\hline E4 & Sim, restaurantes que atendam delivery e por quilo. \\
\hline E6 & $\begin{array}{l}\text { Opções de torradinhas e croutons, bem como molhos para acompanhar a salada de tipos diversificados } \\
\text { não industrializados. Mais opções de sucos seriam interessantes. }\end{array}$ \\
\hline E10 & Para aprimorar não, porém acredito que falte uma divulgação mais efetiva destes estabelecimentos. \\
\hline E12 & Diversificar, criar novas receitas, preço acessível. \\
\hline E14 & Vejo um interesse nicho em delivery de comida vegetariana. \\
\hline E21 & $\begin{array}{l}\text { Além da que já sugeri no item anterior, sugiro também uma melhor divulgação dos restaurantes, } \\
\text { promoções (como cartão fidelidade, alguns já possuem). }\end{array}$ \\
\hline E26 & $\begin{array}{l}\text { Aqui em Cascavel, os restaurantes que já fui, todos são abertos apenas no almoço, não existindo } \\
\text { lugares com muitas opções vegetarianas para jantar. Além disso, esses restaurantes não abrangem } \\
\text { a população vegana. Seria interessante um restaurante livre de qualquer produto de origem animal. }\end{array}$ \\
\hline E27 & Mais variedades em pratos quentes; vegetariano não come só salada. \\
\hline E29 & Ser a quilo e oferecer opções para quem não é fã de salada crua. \\
\hline E38 & $\begin{array}{l}\text { A cidade precisa de mais restaurantes vegetarianos de boa qualidade, atualmente são apenas dois, } \\
\text { bem como deveria haver mais opções de comidas para veganos e mais opções de acompanhamentos } \\
\text { sem ser sempre a proteína de soja. }\end{array}$ \\
\hline E39 & Mais qualidades nos pratos. \\
\hline E41 & Divulgação. \\
\hline E42 & Ofertar a opção "por quilo". Em geral, os restaurantes vegetarianos que frequento cobram por pessoa. \\
\hline E46 & Buffet por quilo. \\
\hline E47 & Atendimento noturno. \\
\hline
\end{tabular}

Fonte: resultado da pesquisa.

Teoria e Evidência Econômica - Ano 23, n. 49, p. 436-461, jul./dez. 2017 
Dessa forma, percebe-se que as preferências e gostos dos consumidores são extremamente diferentes. Retomando o Gráfico 3, em que 23,6\% dos entrevistados afirmam que a diversidade dos alimentos é o principal fator que os levam a frequentar os restaurantes vegetarianos, observa-se um contraste com os depoimentos dos entrevistados E12, E27, E29 e E38, para os quais a diversificação dos alimentos é uma carência do setor.

Em relação à inserção do restaurante indiano em Cascavel, os entrevistados argumentaram que:

E38: Não conheço comida indiana e comi poucas vezes comida chinesa, ou japonesa e queria ter mais essa alternativa em Cascavel.

E55: Hoje em dia tem muita porcaria que é vendida por aí, seria muito bom se tivesse um restaurante vegetariano hindu e de comida selecionada.

E99: Como uma dica, gostaria de acrescentar que no único shopping da cidade, que tem horário estendido para nos alimentarmos, tivesse uma opção dessas, seria muito bem-vinda.

Pelos depoimentos dos entrevistados, percebe-se que a decisão de frequentar um restaurante vegetariano é uma decisão extensiva ou complexa, conforme Paixão (2011), pois envolve mais tempo e mais envolvimento por parte do consumidor em procurar estes locais, já que a divulgação é deficiente (ou não apropriada). Considerando o cenário exposto e os depoimentos dos entrevistados, elaborou-se a matriz de análise SWOT, a qual está exposta na Figura 2.

No ambiente interno, os pontos fortes são fatores essenciais à competitividade dos restaurantes. Dessa forma, maior investimento por parte dos restaurantes nestes pontos melhoraria a competitividade e lucratividade, além de atrair e fidelizar mais clientes. Os pontos fracos encontrados durante a pesquisa são fatores que, se houver mais atenção dos proprietários, podem se tornar pontos fortes, aumentando também o número de clientes.

No ambiente externo aos restaurantes, percebe-se a existência de muitas oportunidades que, com relativamente pouco investimento, podem ser aproveitadas pelos restaurantes. $\mathrm{O}$ crescimento da cultura vegetariana/vegana é uma oportunidade que os restaurantes podem aproveitar para suprir o ponto fraco da falta de opções de pratos para veganos. O fato de haver poucos restaurantes em Cascavel também é uma boa oportunidade para o crescimento dos restaurantes existentes. Contudo, a falta de divulgação deve ser suprida. 
Figura 2 - Matriz de análise SWOT

\begin{tabular}{|l|l|}
\hline E3 & Criar pratos e saladas que despertem o interesse em consumir ao olhar, fazer formas e cores. \\
\hline E4 & Sim, restaurantes que atendam delivery e por quilo. \\
\hline E6 & $\begin{array}{l}\text { Opções de torradinhas e croutons, bem como molhos para acompanhar a salada de tipos } \\
\text { diversificados não industrializados. Mais opções de sucos seriam interessantes. }\end{array}$ \\
\hline E10 & $\begin{array}{l}\text { Para aprimorar não, porém acredito que falte uma divulgação mais efetiva destes } \\
\text { estabelecimentos. }\end{array}$ \\
\hline E12 & Diversificar, criar novas receitas, preço acessível. \\
\hline E14 & Vejo um interesse nicho em delivery de comida vegetariana. \\
\hline E21 & $\begin{array}{l}\text { Além da que já sugeri no item anterior, sugiro também uma melhor divulgação dos restaurantes, } \\
\text { promoções (como cartão fidelidade, alguns já possuem). }\end{array}$ \\
\hline E26 & $\begin{array}{l}\text { Aqui em Cascavel, os restaurantes que já fui, todos são abertos apenas no almoço, não existindo } \\
\text { lugares com muitas opções vegetarianas para jantar. Além disso, esses restaurantes não } \\
\text { abrangem a população vegana. Seria interessante um restaurante livre de qualquer produto de } \\
\text { origem animal. }\end{array}$ \\
\hline E27 & Mais variedades em pratos quentes; vegetariano não come só salada. \\
\hline E29 & Ser a quilo e oferecer opções para quem não é fã de salada crua. \\
\hline E38 & $\begin{array}{l}\text { A cidade precisa de mais restaurantes vegetarianos de boa qualidade, atualmente são apenas } \\
\text { dois, bem como deveria haver mais opções de comidas para veganos e mais opções de } \\
\text { acompanhamentos sem ser sempre a proteína de soja. }\end{array}$ \\
\hline E39 & Mais qualidades nos pratos. \\
\hline E41 & Divulgação. \\
\hline E42 & $\begin{array}{l}\text { Ofertar a opção "por quilo". Em geral, os restaurantes vegetarianos que frequento cobram por } \\
\text { pessoa. }\end{array}$ \\
\hline E46 & Buffet por quilo. \\
\hline E47 & Atendimento noturno. \\
\hline
\end{tabular}

Fonte: resultado da pesquisa.

As ameaças encontradas dizem respeito à tradição cultural de Cascavel, porém, a curiosidade em conhecer culturas diferentes é uma oportunidade que pode acabar com essa ameaça, caso os restaurantes saibam lidar com tal situação. Uma das formas seria suprindo a falta de divulgação e de opções para veganos.

Salienta-se que a análise da Matriz SWOT vai além da percepção dos agentes envolvidos, considerando, também, dados secundários relacionados à posição geográfica, cenário econômico do país e da região, aspectos de demanda agregada, entre outros fatores. Contudo, para atender ao propósito desta pesquisa, apenas a percepção dos donos dos restaurantes e dos clientes foi utilizada, pois, entende-se que a partir da visão destes agentes pode-se ter subsídios para a formulação de novas pesquisas, abrangendo os demais fatores. 


\section{Considerações finais}

Este trabalho teve como objetivos verificar a satisfação do consumidor em relação aos restaurantes vegetarianos existentes na cidade de Cascavel (Paraná) e verificar qual seria o comportamento do consumidor perante a inserção de um restaurante indiano na cidade. Outrossim, analisaram-se os pontos fortes e fracos e as oportunidades e ameaças existentes no contexto dos restaurantes vegetarianos em Cascavel.

Os resultados mostraram que os consumidores entrevistados estão satisfeitos com o atendimento dos restaurantes vegetarianos da cidade, havendo aprovação de $90 \%$. Dos que frequentam restaurantes vegetarianos, $47,1 \%$ são não vegetarianos e $65 \%$ são mulheres. A maioria dos vegetarianos - 45\% - há mais de 5 anos.

De todos os entrevistados, a maioria, 30\%, encontra-se na faixa etária de 20 a 25 anos de idade; $9 \%$ declararam já ter experimentado a comida indiana e, daqueles que não a conhecem, $66 \%$ têm interesse em conhecer. Desses, 56\% declararam que nunca tiveram a oportunidade de experimentar, enquanto $28 \%$ disseram não ter coragem. Das qualidades e serviços que os entrevistados esperam que um restaurante indiano possua destacam-se: o preço acessível (32\%); o atendimento (27\%); a proximidade (44\%); e o estacionamento próprio (38\%).

Além disso, pagãos entrevistados declararam que pagam, em média, entre $\mathrm{R} \$$ 10,00 e $R \$ 15,00$ para almoçar (32\%) e entre $R \$ 25,00$ e $R \$ 50,00$ para jantar (34\%) nos restaurantes vegetarianos que frequentam. A disponibilidade em pagar por um almoço e jantar em um restaurante indiano seguiu a mesma tendência. A maioria está disposta a pagar entre $R \$ 10,00$ e $R \$ 15,00$ para almoçar (44\%) e entre $R \$$ 25,00 e $\mathrm{R} \$ 50,00$ para jantar $(47 \%)$.

Das carências existentes, segundo os entrevistados, destacam-se: opção de torradas e croutons, molhos para acompanhar a salada, e mais opção de sucos à disposição dos clientes. De acordo com os entrevistados, a cidade de Cascavel deveria ter maior diversidade de restaurantes vegetarianos, pois a cidade está crescendo e precisa ter mais opções disponíveis de forma a absorver a demanda por alimentação diferenciada. Outrossim, foi sugerida a opção de restaurantes que disponibilizem buffet por quilo e que ofereçam jantar, com maior flexibilização de horários e atendimento noturno e, também, maior diversidade de alimentação (sanduíches, saladas, novos temperos). Esses depoimentos evidenciam que o mercado tem necessidade de inovação, o que é uma oportunidade que pode ser aproveitada pelos restaurantes, uma vez que existe demanda. 
Da análise SWOT, percebe-se que as oportunidades encontradas podem suprir os pontos fracos dos restaurantes, caso haja investimentos maiores para ampliação e diversificação, além de divulgação. As ameaças também podem ser minimizadas com mais investimentos em marketing e propaganda, além de mostrar à população os benefícios de uma alimentação saudável.

Destaca-se que esse estudo encontrou limitações na aplicação dos questionários, uma vez que nos horários das entrevistas os entrevistados estavam em horário de almoço e, por esse motivo, muitos se recusaram a responder a pesquisa. No entanto, tentou-se destacar alguns dos elementos principais para a análise do comportamento do consumidor e algumas perspectivas estratégicas que podem ser aproveitadas pelos atuais donos dos restaurantes.

Dessa forma, sugere-se que se desenvolvam pesquisas com os proprietários de restaurantes tradicionais para tentar entender o porquê que, em Cascavel, todos os restaurantes vegetarianos são de propriedade estrangeira. Será que nenhum brasileiro percebeu o potencial desse nicho de mercado? Além disso, pode ser feita a ampliação da amostra de forma a abranger maior número de consumidores para que os resultados possam fornecer subsídios para uma análise de viabilidade de implantação de um restaurante indiano, o que não foi o foco desta pesquisa. 


\title{
Comportamiento del consumidor en relación a los restaurantes vegetarianos y perspectiva de un restaurante con comida hindú en Cascavel/PR
}

\begin{abstract}
Resumen
Este artículo tiene como objeto analizar la satisfacción del consumidor con los restaurantes vegetarianos existentes en la ciudad de Cascavel, como también verificar el comportamiento de los consumidores con la instalación de un restaurante hindú en la ciudad. Además se busca analizar puntos positivos y negativos, como así también las oportunidades y amenazas existentes en los restaurantes vegetarianos en Cascavel. Para que este objetivo tenga resultados, se formuló un cuestionario, el mismo se aplicó a clientes de tales restaurantes, bien como a personas en general por las calles de la referida ciudad. El resultado ha sido que el noventa por ciento $(90 \%)$ de los mismos han demostrado buena satisfacción con el menú y atendimiento en tales restaurantes. Ya con la instalación de un restaurant hindú un sesenta y seis por ciento $(66 \%)$ de los que respondieron el cuestionario demuestran interés en conocer la cocina hindú; el cuarenta y cuatro por ciento (44\%) estarían dispuestos a pagar la suma de \$ 10 BRL o \$ 15 BRL para almorzar y un cuarenta y siete por ciento (47\%) la suma de $\$ 25$ BRL y $\$ 50$ BRL para cenar en restaurantes de comida hindú. Las oportunidades encontradas pueden suplir los puntos negativos de restaurantes, si se logra más inversiones para que se pueda ampliar y diversificar, además de divulgación. Las amenazas también se pueden disminuir con inversiones en marketing y propaganda, además en concienciar a la población los beneficios de una comida saludable.
\end{abstract}

Palabras clave: comportamiento del consumidor; disponibilidad en pagar; cultura india.

\section{Consumer behavior with regard to vegetarian restaurants and perspective of an indian restaurant in Cascavel/PR}

\begin{abstract}
This paper aims to assess the consumer's satisfaction with the existing vegetarian restaurants in the Cascavel city and the consumer's behavior related to the insertion of an Indian restaurant in the city. In this sense, we analyze the strengths and weaknesses, the opportunities and threats in the context of vegetarian restaurants in Cascavel. To this end, a questionnaire was formulated, in which the application occurred randomly in vegetarian restaurants and on the streets. The results showed that the consumer from Cascavel is satisfied with the service of vegetarian restaurants in the city, with approval of $90 \%$ of respondents. With regard to consumer's behavior in relation to the insertion of an Indian restaurant in the city, $66 \%$ of respondents were willing to meet Indian food; and $44 \%$ would be willing to pay between $R \$ 10.00$ and $R \$ 15.00$ for lunch and $47 \%$ would be willing to pay between $R \$ 25.00$ and $\mathrm{R} \$ 50.00$ for dinner at an Indian restaurant. The opportunities found can supply the weaknesses of restaurants, if there is greater investment for expansion and diversification, as well as publicizing. Threats can also be minimized with more investments in marketing and advertising, as well as show the population the benefits of healthy feed.
\end{abstract}

Key words: Consumer behavior, Vegetarianism, Indian Culture. 


\section{Notas}

1 Para maiores detalhes sobre esta teoria, ver Ajzen (1991) e Giampietri Finco e Del Giudice (2016).

2 Um dos restaurantes foi fechado recentemente, porém, quando esta pesquisa foi realizada ele ainda estava em funcionamento, por isso será considerada a existência de quatro restaurantes vegetarianos em Cascavel.

3 Este percentual corresponde apenas aos 51 entrevistados que frequentam os restaurantes vegetarianos.

4 Este percentual considera todos os 176 entrevistados.

\section{Referências}

AJZEN, I. The theory of planned behavior. Organizational Behavior and Human Decision Processes, v. 50, n. 2, p. 179-211, Dec. 1991.

AMERICAN DIETETIC ASSOCIATION - ADA. Position of the American dietetic association and dietitians of Canada: vegetarian diets. Journal of the American Dietetic Association, v. 103, n.6, p. 748-765, Jun. 2003.

BARBETTA, P. A. Estatística aplicada às ciências sociais. 5. ed. Florianópolis: Editora da Ufsc, 2002.

BEIG, B. B. A prática vegetariana e os seus argumentos legitimadores: viés religioso. Revista Nures, São Paulo, n. 11, jan./abr., 2009.

BINKLEY, J. K. Demand for fast food across metropolitan areas. Journal of Restaurant and Foodservice Marketing, v. 3, n. 1, p. 37-50, 1998.

DANTAS, N. G. S.; MELO, R. S. O método de análise SWOT como ferramenta para promover o diagnóstico turístico de um local: o caso do município de Itabaiana/PB. Caderno Virtual de Turismo, Rio de Janeiro, v. 8, n. 1, p. 118-130, 2008.

ECKHARDT, G. M.; MAHI, H. Globalization, consumer tensions, and shaping of consumer culture in India. Journal of Macromarketing, v. 32, n. 280, April 2012.

ENGEL, J.; BLACKWELL, R.; MINARD, P. Consumer behavior. 8. ed. Fort Worth: Irwin, 1995.

GIAMPIETRI, E., FINCO, A., DEL GIUDICE, T. Exploring consumers' behaviour towards short food supply chains. British Food Journal, v. 118, n. 3 p. 618-631, 2016.

GIL, A. C. Métodos e técnicas de pesquisa social. 6. ed. São Paulo: Atlas, 2008.

GODOY, A. S. Pesquisa qualitativa: tipos fundamentais. Revista de Administração de Empresas, São Paulo, v. 35, n. 3, p. 20-29, maio/jun. 1995.

GONÇALVES, A. T. P. Análise de conteúdo, análise de discurso e análise de conversação: estudo preliminar sobre diferenças conceituais e teórico-metodológicas. Administração: Ensino e Pesquisa, v. 17, n. 2, p. 275-300, 2016.

HOEK et al., A. C. Food-related lifestyle and health attitudes of Dutch vegetarians, non-vegetarian consumers of meat substitutes, and meat consumers. Appetite, n. 42, p. 265-272, 2004.

INSTITUTO BRASILEIRO DE GEOGRAFIA E ESTATÍSTICA - IBGE. IBGE Cidades. Cascavel: população estimada 2016. Disponível em: <http://cidades.ibge.gov.br/xtras/perfil. php?codmun=410480>. Acesso em: 13 set. 2016. 
JOHNS, N.; PINE, R. Consumer behavious in the food service industry: a review. Hospitality Management, n. 21, p. 119-134, 2002.

KARSAKLIAN, E. Comportamento do consumidor. 2. ed. São Paulo: Atlas, 2008.

MANKIW, N. G. Princípios de microeconomia. 6. ed. São Paulo: Cengage Learning, 2013.

MEIRELLES, C. M.; VEIGA, G. V.; SOARES, E. A. Vegetarian diets: characterization, nutritional implications and contr oversies. NUTRIRE: Revista da Sociedade Brasileira de Alimentação e Nutrição, São Paulo, v. 21, p. 57-72, jun., 2001.

MELINA, V.; DAVIS, B.; HARRISON V. A dieta saudável dos vegetais: o guia completo para uma nova alimentação. Rio de Janeiro: Campus, 1998.

NAYGA, R. M.; CAPPS, O. Impact of socio-economic and demographic factors on food away from home consumption: number of meals and type facility. Journal of Restaurant and Foodservice Marketing, v. 1, n. 2, p. 45-69, 1994.

NEVES, M. F.; CASTRO, L. T. Marketing e estratégia em agronegócios e alimentos. São Paulo: Atlas, 2003.

NUNES, E. L. M. Vegetarianismo além da dieta: ativismo vegano em São Paulo. 2010. Dissertação (Mestrado em Ciências Sociais) - Pontifícia Universidade Católica de São Paulo, São Paulo, 2012.

PAIXÃO, M. V. Pesquisa e planejamento de marketing e propaganda. 2. ed. Curitiba: IBPEX, 2011.

PAQUETTE, M. C. Perceptions of healthy eating: state of knowledge and research gaps. Canadian Journal of Public Health, v. 96, suppl. 3:S15-9, S16-21, Jul./Aug. 2005.

PERNER, L. Consumer behavior: the psichology of marketing. Los Angeles: USC, 2017.

POLLONIO, M. A. R. Impactos da globalização na segurança de alimentos. Universidade Estadual de Campinas. Campinas, 2005. Disponível em: <http://www.fooddesign.com.br/arquivos/ academia/marise_pollonio_impactos_da_globalizacao_na_seg_alim.pdf>. Acesso em: 27 ago. 2016.

PRIORI et al., A. História do Paraná: séculos XIX e XX. Maringá: Eduem, 2012.

RECINE, E.; RADAELLI, P. Alimentação e cultura. Brasília: Ministério da Saúde; 2008.

ROZIN, P. The integration of biological, social, cultural and psychological influences on food choice. In: SHEPHERD, R.; RAATS, M. The psychology of food choice. Oxfordshire: Cabi, p. 19-40, 2006.

SINGER, P. Libertação animal. São Paulo: WMF Martins Fontes, 2010.

SPENCER, C. Vegetarianism: a history. 2. ed. New York: Four Walls Eight Windows, 2002.

TEIXEIRA, J. C. I. Fatores que influenciam o comportamento do consumidor. 2010. Trabalho de Conclusão de Curso (Especialização em Gestão Estratégica de Vendas e Negociação) - Universidade Cândido Mendes, Instituto A vez do Mestre, Rio de Janeiro, 2010.

TREW et al. K. Adolescents, food choice and vegetariasnism. In: SHEPHERD, R.; RAATS, M. The psychology of food choice. Oxfordshire: CABI, p. 247-262, 2006 (cap. 13).

TWIGG, J. Food for thought: purity and vegetarianism. Religion, v. 9, Spring, p. 13-35, 1979. 
WILCOCK et al. Consumer attitudes, knowledge and behavior: a review of food safety issues. Trends in Food Science \& Technology, n. 15, p. 56-66, 2004.

WINKLER, Marly. Fundamentos do vegetarianismo. Rio de Janeiro: Expressão e Cultura, 2004.

YIN, R. K. Estudo de caso: planejamento e métodos. 2. ed. Porto Alegre: Bookman, 2001. 